Original Research Article

\title{
Analysis and Solution of the Problems in the Distribution of Suning Tesco
}

\author{
Canlong Lin,Jinghui Zhu,Jianhua Peng \\ School of Logistics Management and Engineering, Yantai University of Technology, Shandong, China
}

\begin{abstract}
Logistics is the 'third party profit source' of the enterprise. At the end of the logistics, the distribution is the core component of the logistics system. It is an important part of the business activities. It is an important part of the enterprise's business activities. It is important to optimize the economic structure, save the social labor and give full play to the logistics function. To a great effect. This article is mainly based on Suning Tesco distribution as the research object, according to the Suning Tesco distribution of the status quo to determine its problems. The analysis of the existing problems and put forward targeted recommendations, so that Suning Tesco distribution can be further optimized.
\end{abstract}

KEYWORDS: Suning Tesco; distribution; business

\section{Suning Tesco introduction}

Suning Tesco, Suning Appliance Group is a new generation of B2C online mall, on August 18, 2009 on-line trial operation. January 25, 2010, Suning Appliance announced in Nanjing headquarters, the company's B2C online shopping platform Suning Tesco will be officially launched on February 1, and will be independent procurement, independent operation, Suning Appliance also officially launched e-commerce BtC field The May 25, 2011 officially enabled. Com domain name, the original. Cn domain name jump to. Com domain name.

Suning Tesco has Suning brand advantage, hundreds of billions of procurement scale advantages, all over the country more than 30 provinces 1000 distribution points more than 3,000 after-sales service network service advantages, continuous innovation and so on. Suning Tesco developed a clear three-year development strategy, built into an independent operating system in line with the Internet economy, the formation of 1,000 people B2C professional operations team, the formation of independent structure, independent sales, shared logistics services characterized by operating mechanism, To the sale of goods and services for consumers, at the same time in collaboration with the physical store will be located in the service store, auxiliary store, the actual interaction, to provide consumers with product information, service status query interaction, and as a new product experimental base, Will be consumer shopping habits, preferences of the research feedback to the supplier design, enhance the entire supply chain flexible production, mass customization.

According to the overall development of the industry and its own development strategy, Suning Tesco plans within 3 years in the Chinese home appliance network purchase market accounted for more than $20 \%$ of the share, becoming China's largest 3C home appliances B2C website.

\section{Suning Tesco delivery mode}

\subsection{To the store distribution}

In accordance with the store ordering information, by the distribution center with the goods, to the store replenishment, which is a typical B $2 \mathrm{~B}$ distribution model. This replenishment is mainly for a variety of small appliances. Distribution center will be the goods to the store, the customer to the store to buy and carry their own home. Such goods are called non-centralized delivery of goods, in total sales accounted for $40 \%$ of the share. The cost of this distribution model is not less and more fixed, the impact of small profits on the enterprise.

Copyright (C) 2017 -. This is an Open Access article distributed under the terms of the Creative Commons Attribution-NonCommercial 4.0 International License (http://creativecommons.org/licenses/by-nc/4.0/), permitting all non-commercial use, distribution, and reproduction in any medium, provided the original work is properly cited. 


\subsection{To the customer delivery}

(1) When the customer in the store to buy home appliances, the store will be the customer's purchase information to the distribution center of the information processing system, the distribution center will focus on different regions, different varieties, the demand for sporadic purchase instructions, according to the customer area distribution The area will be reorganized after the goods by the distribution site to reach the user, which is a typical B2C logistics model. This distribution is the distribution center direct delivery to the customer, but the distribution to the store, thus saving the transportation costs of distribution, reducing the risk of distribution and transportation.

(2) Customers buy online appliances, the order information automatically generated in the system, and then sent by the workers quickly and correctly sent by the delivery master by delivery orders and fast delivery of goods quickly and secure hands. It is also B2C logistics model. Its distribution can be quickly and accurately the distribution and can give customers see the entire distribution of information.

\subsection{Distribution to distribution center}

When other areas of the distribution center out of stock and out of stock. it will be another to its goods and adequate distribution center issued a transfer order, requiring large quantities of distribution. This is Suning Tesco allocated B2B distribution model. This distribution model can quickly make up for manufacturers cannot hurry to a distribution center delivery, greatly improving the profits of enterprises.

\section{Analysis on the Present Situation of the Distribution of}

\subsection{Suning easy to buy rain flower distribution center}

Yuhua base of the logistics and distribution center using ordinary shelves and automated warehouse combination of the construction of the warehouse area of 46,000 square meters, the introduction of advanced storage, handling, transportation, sorting equipment and information management system, can achieve the mechanization of logistics, Automation, information operation and management, daily handling capacity up to the largest storage 17,000 units, the largest out of 24,000 units. Logistics distribution center using WMS (Warehouse Management System) warehouse management system, can effectively support different users of different information needs, more reasonable balance of workloads, reduce the level of errors, improve inventory accuracy and storage space utilization, reduce operating costs. Another important core software system for the logistics distribution center The TMS (Transportation Management System) transportation management system is designed to optimize the manual scheduling for retail distribution and long-haul distribution of orders, to optimize route scheduling, to effectively reduce mileage and working hours Mode of operation. Plans to establish a multimedia monitoring system, including image monitoring, communication video, information aggregation, command and other functions, you can all the chain stores, logistics centers, after-sales outlets to monitor and real-time management. Upon completion, Suning Logistics Distribution Center can achieve $24 \mathrm{~km}$ within $24 \mathrm{~km}$ direct door-to-door, support annual sales of 12 billion yuan.

Distribution center planning Bingzhe modern logistics concept, the whole use of more system technical services to customers.

(1) Suning Yi Fu Bao. Relying on the Suning more than 1,200 Suning Yi Fu Bao, creating a new mode of payment. Customers in Suning stores recharge, online consumption, so that customers in the online shopping consumption at the same time, feel the payment of security assurance.

(2) Telephone payment mode. Suning phone payment is the first domestic electronic retail industry, greatly facilitate the customer online shopping experience.

(3) Suning sun package, IT help customer sales. Suning as a free service products, Suning sun package, IT help people to innovate the concept of after-sales service products.

(4) Localized delivery, large appliances free shipping. Relying on the Suning national logistics, after-sales system, Suning Tesco can do the audience free shipping and free installation.

(5) Membership card. Suning membership card in the Suning Mall and the National Suning Appliance stores, such as your holdings in Suning stores for membership cards, to purchase in Suning Toua need to bind the membership card in advance to the shopping the points are credited to the original membership card account.

\subsection{Suning Tesco distribution system}

Suning Tesco distribution process to order as the center, marketing, logistics and procurement in a unified platform. In this platform, the online order information can be immediately passed to the distribution center, by the 
distribution center to respond, resulting in distribution instructions. Whether it is Suning Appliance's own vehicles, or outsourcing vehicles, in the completion of a task, we must first go to the information hall for a library procedures, to receive a library. And then go to the Treasury delivery, delivery. Upon completion of the order, but also to the information hall to write off the task.

With the support of advanced information systems, Suning has carried out precise control of the flow of goods. In the warehouse delivery orders through the warehouse staff after careful check, the goods from the warehouse handling, loading and unloading to the vehicle, due to full mechanization, the efficiency of shipment is very high, filled with a car only ten minutes.

For Suning Tesco, logistics is its smooth operation, the key to healthy development, from the procurement, storage, distribution to after-sales service, Suning Tesco operation must have efficient logistics system to protect. The construction of the logistics system is also one of the core contents of Suning chain strategy. At present, Suning in stepping up the construction of the third generation of information logistics base, which uses fully automated, mechanized three-dimensional storage system integration program, through the warehouse three-dimensional warehouse system, mechanized transport system, WMS and TMS warehouse management system implementation, Will be built within the domestic electrical chain industry's most advanced logistics center, a new generation of Suning Appliance logistics system operation and development of the landmark project.

At present, Suning Appliance has built the third generation logistics center for the Jiangsu logistics center, is the construction of the Shenyang logistics center, about to build, including Beijing, Wuxi, Chengdu, Xuzhou and Chongqing logistics center. The third generation logistics center will assume the long distance transfer $(300 \mathrm{~km})$ of the goods sold in the surrounding area of the logistics center; store distribution, retail distribution (within $150 \mathrm{~km}$ ); pipeline transportation and stent distribution. After completion, can meet the $50 \sim 10$ billion annual turnover of goods operating requirements.

Has been completed in Jiangsu logistics center in accordance with the 'professional division of labor, standardized operations, modular structure, hierarchical management' standard construction. In Nanjing, the establishment of radiation within $150 \mathrm{~km}$ of the city's distribution, storage area of 46,000 square meters, the full application of mechanization, automation, information technology of modern logistics equipment and systems, storage capacity of 300 million sets of daily operating capacity of 30,000 Taiwan sets, support sales of 30 billion yuan.

\subsection{Suning Tesco distribution characteristics}

\section{(1) Timeliness}

Suning Tesco is a company that is dedicated to serving customers and must respond quickly to customer needs. This requires Suning Tesco to have a very good ability to quickly reflect the information unimpeded, as far as possible in the shortest possible time to the goods to the hands of customers. Suning's logistics and distribution is divided into two periods, the day 12: 00-18: 00 generated orders, the next day before 12:00 before delivery; the same day 18:00 - 12:00 the next day to generate the order and the next day 22: 00 before delivery is complete. That is, Suning Tesco signs: 1200

\section{(2) Communication}

Logistics distribution is a logistics terminal services, direct contact with customers, must be active and effective communication. Such as confirming the customer to buy the product, delivery time, delivery location and so on. Suning Tesco asked each worker to confirm whether the customer has time before delivery, by reducing the Suning reverse logistics, reducing the logistics costs of Suning. In addition, Suning Tesco set up online customer service online and sales online, customers can be the first time with Suning Tesco contact. In the customer's order information in the logistics and distribution of the entire process of specific instructions to the staff, time, place and so on.

\section{(3) Diffuse}

Commodity distribution As a result of the user, the traffic line is complicated, how to combine into the best route, how to make the match and the line with the effective, is Suning Tesco delivery and transportation of another feature, but also Suning Tesco delivery of transport tasks in the difficult. Suning Tesco uses the SAP system selfaggregates customer data to optimize the distribution route for the customer. And by the workers to send workers to form a simple form of zero.

\section{(4) Seasonal}

The seasonal differences in merchandise sales are obvious, especially for those seasonal products. Such as air conditioning, refrigerator sales season generally in the summer, warm baby, foot tub sales season generally in autumn and winter season. Season sales are several times higher than the off-season. In addition, due to the impact of holiday business promotion, some goods will be sold during the holidays. This is what Suning called 'busy.'

(5) Convenient 
Commodity distribution as a value-added services, must meet the maximum customer requirements, to provide customers with convenient services. Suning easy to buy online sales line, the customer according to their own situation choose to buy. In addition, online purchase has become the first choice for customers, because it is more convenient and more convincing

\section{Analysis of Suning Tesco delivery problems}

Since 2009, Suning Tesco distribution system is still in the initial stage of construction, mainly in its lack of standardized operating procedures. Distribution staff arbitrarily strong, the lack of distribution processes and distribution lines for scientific and rational planning. In the logistics and distribution costs are not very good frugality, cannot reach a cost concept, is in the trial operation of the primary model. Suning Tesco distribution of the overall existence of the following questions:

\subsection{Logistics distribution market is low, third-party logistics and distribution development lag.}

At present, Suning Tesco's technical equipment and management methods are relatively backward, service network and information system is not perfect, logistics and distribution of a low degree of market logistics, affecting the accuracy and timeliness of its logistics and distribution services. The main performance is: rarely provide logistics planning, organization and in-depth to the whole process of supply chain management, logistics value less; development lag, specialization, information, standardization has not kept up, not really understand the international logistics enterprises Mode of operation and the true sense of the 'third party logistics'. Suning Tesco currently free access to the majority of vehicles, restricting the development of third-party logistics.

\subsection{Logistics infrastructure behind, the overall function of logistics and distribution is low.}

(1) Transportation and transportation facilities construction and logistics and distribution needs are incompatible, that is, transportation capacity still cannot meet the transport needs, the main transport channel supply and demand is still outstanding. Suning Tesco's existing warehousing facilities, such as automated warehouse, have the hardware conditions for the development of logistics, but need to strengthen the logistics information management tools, modern logistics facilities and the corresponding equipment.

(2) Technical and equipment level behind, increasing the cost of distribution and transportation. Efficient special transport vehicles less; car to medium-sized gasoline vehicles, energy consumption, low efficiency; loading and unloading of the low level of mechanization.

(3) The logistics system standardization is low. The efficient operation of the logistics business (such as trays, trucks and shelves) standardization and information system standardization, that is, all aspects of the supply chain to use a unified standard, all aspects of information systems can dock, exchange data, share information. For example, the transport of European and American countries are based on $1 \times 1.2$ tray as a unit of calculation, the standard unified, statistical convenience, improve transport, storage and handling and other aspects of efficiency, with the goods traveled Europe and the United States. And Suning Tesco in the standardization, and some use of a generation of library standards, and some use of second-generation library standards, as well as the third generation of library standards, and thus to the various aspects of logistics docking caused inconvenience, affecting the logistics operation efficiency. (Without standardization as shown)

\subsection{Distribution center is not scientific}

At present, Suning Tesco in the distribution center site selection, due to the lack of understanding of the importance of site selection decision, simply consider the storage rent, rarely combined with distribution costs, distribution efficiency and quality of service to analyze. From the surface, a one-time fixed storage rental investment less, but in fact because of the warehouse location of the remote, poor traffic conditions, delivery distance is longer, high cost of delivery, the carrier, the single The volume is small, the delivery efficiency is affected, in order to ensure a reasonable income of the vehicle, acceptable delivery tariffs on the high. So the efficiency of distribution on the greatly reduced, cannot quickly put the goods into the hands of customers. And the increase in the distance to increase the distribution costs.

\subsection{Professional logistics and distribution management and technical talent shortage.}

From other enterprises logistics and distribution development experience, enterprises require logistics and distribution practitioners should have a certain level of logistics knowledge and practical experience. Should form a more reasonable logistics personnel education and training system, in a considerable number of universities to recruit 
logistics management professionals, and extensive business management for the professional students to set up logistics courses. In contrast, Suning Tesco logistics and distribution of talent education is still relatively backward, has not yet established a sound logistics education system and personnel training system, leading to a very lack of professional logistics personnel. At the same time, the quality of logistics and distribution practitioners is low, lack of service consciousness and lack of initiative of market development. Can be efficient and scientific management of logistics and distribution, and familiar with the modern logistics and distribution operations and logistics and distribution of complex professional high-level talent is more scarce, this issue restricts the Suning Tesco logistics and distribution of further development.

\section{Suning Tesco delivery of the settlement measures}

\subsection{Build and improve the logistics and distribution information system.}

Logistics distribution information system is to support the logistics and distribution of information flow system, logistics and distribution is through the information system to obtain accurate market conditions and other subsystems and start the operation of the situation. A sound logistics information system construction and development is to enable logistics and information flow to coordinate the operation, so as to achieve smooth distribution, improve efficiency.

(1) To establish a good profit and Suning Tesco distribution of logistics information system, which in the logistics and distribution of operating systems to establish a stable information between the channels to achieve effective customer feedback and the close cooperation between the operating system, Coordinated development and thus increase the degree of marketization.

(2) To have a scientific and efficient logistics and distribution management application software, the establishment of distribution management information system.

(3) The development of third-party logistics to reduce the operating costs of logistics and distribution, combined with Suning Tesco set up technical service team for after-sales technical services; the establishment of logistics alliances, and more stable business customers to form an allies to achieve logistics Distribution scale effect.

\subsection{To increase logistics infrastructure construction}

(1) Reasonable construction of transport facilities

Suning Tesco can build transportation facilities according to its own distribution mode. If the goods are more expensive and the distribution distance is shorter, it is necessary to choose shipping and air cargo transport. This will help to enhance the logistics capacity, reduce the waste of resources and manpower, and effectively reduce the logistics process due to complex process, repeat the problem.

(2) Enhance the concept of logistics, and promote the construction of logistics facilities and equipment

To maximize the concept of saving logistics costs, the development of its technical equipment. Finally, Suning also give the appropriate facilities and equipment investment, promote the development of logistics facilities and equipment.

(3) The standardization of logistics construction

Suning Tesco should speed up the pace of standardization, the development of logistics standard system, for the logistics needs behind the development of the standard should be eliminated, replaced by the development of logistics standards for the development of Suning Tesco in the logistics of the existing problems and other corporate logistics development direction new standard. Such as the development of a unified tray.

\subsection{Scientific Choice Distribution Center Address}

In the process of urban modern logistics system planning, the location of the distribution center should consider the following factors:

\section{(1) Natural environmental factors}

Weather condition. In the distribution center selection process, the main consideration of meteorological conditions are temperature, wind, precipitation, frost-free period, permafrost depth, the average annual evaporation and other indicators. Such as the location to avoid the outlet, because the construction in the outlet will accelerate the aging of the open-shelf goods.

Geological conditions. Distribution center is a large number of goods gathering place. If the distribution center below the ground there are muddy layer, flow sand layer, loose soil and other adverse geological conditions, will be 
caused by the pressure in the subsidence, fog and other serious consequences, for which the distribution center location requirements of soil capacity is higher.

Hydrological conditions. The distribution center is located away from the easily flooded river basins and areas where the groundwater is flooded. To seriously examine the hydrological data in recent years, the groundwater level cannot be too high, flood area, waterlogging area, so the river, dry river beach and other areas are absolutely prohibited to use.

Terrain conditions. Distribution center should choose a higher terrain, terrain flat, and should have the appropriate area and shape. If you choose in a completely flat terrain is the best, followed by a slight slope or undulating place; for mountainous areas should be completely avoided. In the shape can choose the rectangle, should not choose narrow or irregular shape.

(2) Operating environment factors

Operating environment. A sufficient number and high quality labor conditions are one of the factors considered in the distribution center.

Commodity characteristics. The distribution centers that operate different types of goods are best available in different areas. Such as the production site distribution center should be with the industrial structure, product mix, industrial layout and other closely to consider.

Logistics costs. Logistics costs are one of the important considerations for the location of the distribution center. It is best to close to the logistics service needs, in order to shorten the distance, to reduce freight and other logistics costs.

\section{(3) The status of infrastructure}

Traffic Conditions. The distribution center must have convenient transportation conditions. It is best to close the traffic hub layout, in order to be able to quickly and correctly distribution.

Status of public facilities. The location of the distribution center, the city's roads, communications and other public facilities are available, there is sufficient power supply, water, heat, gas capacity, and the area around the sewage, solid waste and other processing capacity. For hydropower and other resources, if it is a large number of facilities required, in the selection process, not only to consider its supply is sufficient, but also to consider whether the cost can bear.

\section{(4) Other factors}

Land and Resources Utilization. The planning of the distribution center should implement the principle of saving land and making full use of land resources. Distribution center generally covers an area of large, around the need to leave enough room for development, the level of land prices on the layout of the planning have an important impact. In addition, the distribution center layout also take into account the regional and urban planning land of other elements.

Environmental protection requirements. The location of the distribution center needs to consider the protection of the natural environment and the human environment and other factors, as much as possible to reduce the interference of urban life. For large-scale transport hub, should be properly set away from the downtown area, making the city's traffic environment can be improved, the city's ecological construction to maintain and enhance.

Peripheral condition. As the distribution center is a fire protection units, should not be located in the easy distribution of fire industrial facilities (such as wood processing, metallurgical enterprises) near, it is not appropriate to choose in residential areas near.

\subsection{Attention to the development of enterprise distribution personnel, the implementation of talent strategy}

Enterprise competition in the final analysis is the talent competition. Only the quality of enterprise distribution practitioners continue to improve, continue to learn and apply advanced technology, methods, in order to build suitable for the development of China's own distribution industry.

(1) To strengthen school-enterprise cooperation. So that students can learn all aspects of Suning in the school to speed up the distribution of professional and technical personnel and management personnel training, creating a large number of familiar with the distribution of the operation of the law, and the pioneering spirit of the talent team to improve the overall quality of enterprises.

(2) To strengthen the distribution of staff arrangements and training. Suning Tesco free distribution staff dispatch driver, Merchandiser, courier three categories. Suning should fully tap the potential of all kinds of personnel, strengthen training, so that employees more professional. 


\section{Conclusion}

This article first analyzes the distribution of Suning Tesco distribution, analyzes its logistics and distribution system, distribution characteristics, summed up the Suning Tesco distribution problems. Then, based on the above analysis and the existing problems, according to the actual situation of Suning Tesco, the corresponding measures are put forward.

\section{References}

1. Wu Qingyi. Logistics Management [M]. Beijing: China Materials Publishing House, 2005.12.

2. Zhang Xiaoyan. On the core competitiveness of supermarket chains [J]. Changzhou: Journal of Changzhou Institute of Technology, 2005 (8): 15-4.

3. WU Cong. Study on Logistics Operation Mode Selection of Chinese Chain Retail Enterprises [J]. Logistics Technology, 2005, (4).

4. Wan Xiao, Zhou Ning. Analysis of Logistics System Distribution in China's Commercial Chain Enterprises [J]. Journal of Northern Jiaotong University, 2003 (6).

5. Journal of Southeast University, 2001 (11): 31-6. [5] Gao Gengjun, Huang Wei.

6. Wang Guanghui, Wang Yuntao. Automatic identification technology in the logistics management application [J]. Logistics Science and Technology, 2005 (1): 15-17.

7. Li important. Development of chain distribution business should pay attention to control product inventory [J] .Hubei: Post Research, 2006 (7): 22-4.

8. Li Zhifeng. Management of logistics and distribution chain management [J]. Logistics Distribution, 2001 (7): 21.

9. Tian Yu, Gong Guohua. 5 to reduce the cost of distribution strategy [J]. Jiangsu Textile, 2001: 4-5.

10. Zhu Hua. Distribution Center Management and Operations [M]. Beijing: Beijing Higher Education Press, 2003.

11. Li Yuhui, Shao Guangya. Chain management of supply chain management [J]. Zhengzhou: Business Research, 2001 (3).

12. Wen Longguang, Shan Shan Ming. Chain operations and logistics and distribution [J]. Economist .2003 (2).

13. Zhou Min. China's retail chain logistics distribution [J]. Wuhan: Contemporary Economy, 2008 (12).

14. Li Wei, the establishment of efficient distribution system to achieve supply chain optimization [J] Beijing: Petroleum Technology, 2002, (4): 20-2.

15. Li Xingguo, Gu Feng. Chain enterprise logistics and distribution model selection strategy research [J]. Hefei: Logistics Technology, 2008 (3).

16. Han Zhihua, Yang Chunyan, Meng Xiangming. Wal-Mart chain business strategy to bring us to think [J]. Qiqihar Teachers College Journal, 2008 